\title{
From quarantine to quality
}

\author{
The Last Plague: Spanish Influenza and \\ the Politics of Public Health in Canada \\ Mark Osborne Humphries \\ University of Toronto Press; 2013
}

$\mathrm{M}$ ark Osborne Humphries' book, The Last Plague: Spanish Influenza and the Politics of Public Health in Canada, speaks to an important time in the development and maturation of Canada's public health infrastructure. The influenza pandemic of 1918 challenged the reigning strategy of quarantine of immigrants. "As traditional strategies failed, public health was politicized as never before" (page 9). Humphries provides new insights into important drivers of the pandemic the "mobilization and transportation of this new Siberian Expeditionary Force spread flu across Canada. The barracks and camps from which these soldiers came were already infected when orders went out in September for the movement of troops to begin" (page 102).

The author describes the importance of social reforms (strengthened by the Women's War Conference) and our increased reliance on sanitation and disinfection, both informed by germ theory. Humoural thinking (the erroneous notion that four distinct bodily fluids determine our traits and behaviours) and bureaucratic inefficiencies remained barriers to change. Vital statistics and surveillance data were exceedingly rudimentary. Most households in Toronto, Ontario had pit privies and in

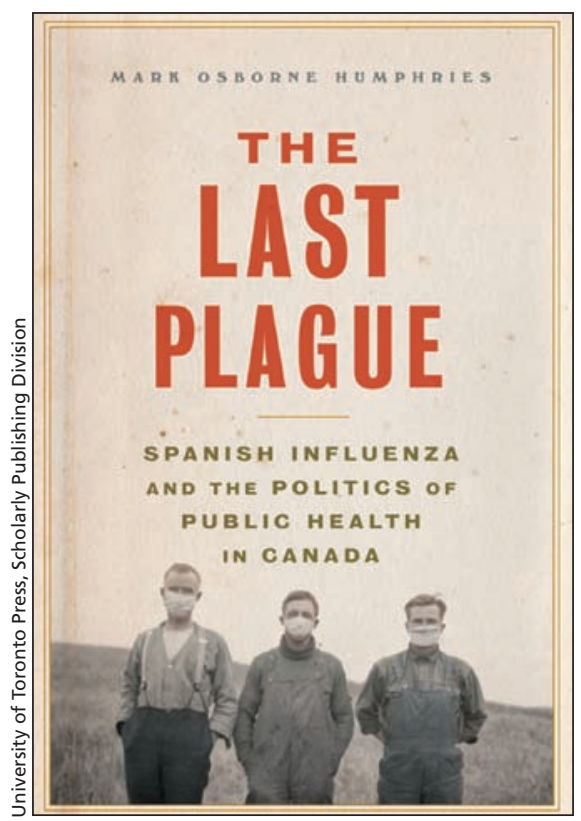

1895 , the infant mortality rate in Montréal, Quebec set a record high for the Western world. Medical therapeutics were limited and sometimes desperate. Some community members demanded access to banned spirits for comfort from the severe symptoms of influenza. The poor suffered in excess as did soldiers newly recruited under the Military Services Act.

The focus and strength of this book is its discussion of the shift in public health legislation from that of late 18th century, which authorized local officials to detain persons with well-known contagious disease, to the first federal act in 1848 . Along with other histories such as Epidemic Encounters: Influenza, Society, and Culture in Canada, 1918-20 to which Humphries makes a contribution, this book helps us piece together our past in the context of new challenges such as SARS, H1N1 and MeRS (Middle East respiratory syndrome). It provides a thorough analysis of the impact that the large number of deaths from influenza had on creating an organized public health body.

Surveillance largely replaced quarantine. Overseas immigration offices closed, and a move toward prevention and food standardization became prominent. Canada responded to the pandemic by adopting a more proactive approach to matters of public health and by forming a centralized agency - Bill 27, which was introduced and given royal assent in 1919 (amid the cancellation of the Stanley Cup finals for public health reasons), led to the formation of a Federal Health Department.

Public health is a complex animal. We now appreciate better health than any population in history. Humphries has greatly contributed to our understanding of the improvement of the health of Canadians with The Last Plague.

\section{Wendy L. Wobeser MD MSc}

Associate professor

Division of Infectious Disease

Queen's University

Kingston, Ont.

\section{Reference}

1. Fahrni M, Jones EW. Epidemic encounters influenza, society, and culture in Canada, 1918-20. Vancouver (BC): UBC Press; 2013.

CMAJ 2014. DOI:10.1503/cmaj.131369 